EDITORIAL

\title{
253 A fresh approach to water
}

NEWS

\section{Purification with a pinch of salt}

Q. Schiermeier

NEWS FEATURES

\section{A long dry summer}

Q.Schiermeier

\section{More crop per drop}

\author{
E. Marris
}

\section{Muddy waters}

D. Fairless

\section{COMMENTARY}

283 Improving on haves and have-nots

J. Bartram

\section{The energy challenge}

M. Hightower \& S. A. Pierce

BOOKS \& ARTS

\section{Water policy in the can}

E. Marris

\section{Echoes of time in images of the Antarctic}

M. Kemp

\section{ESSAY}

\section{Water - an enduring mystery} P. Ball

\section{REVIEW}

\section{Science and technology for water purification in the coming decades}

M. A. Shannon, P. W. Bohn,

M. Elimelech, J. G. Georgiadis,

\section{B. J. Mariñas \& A. M. Mayes}

M ore than a billion people do not have access to safe drinking water and two billion have inadequate sanitation. This is despite two international decades, a millennium declaration goal, two international years and a string of global celebratory days - all dedicated to drinking-water or sanitation. Why has progress been so slow?

One reason could be that the current global targets - the Millennium Development Goals - do not provide sufficient incentives for all nations to ensure that everyone has access to water and sanitation (see page 283). Another reason is that the pressures on water resources are continuing to rise: whether through population growth, economic development or climate change (see page 270).

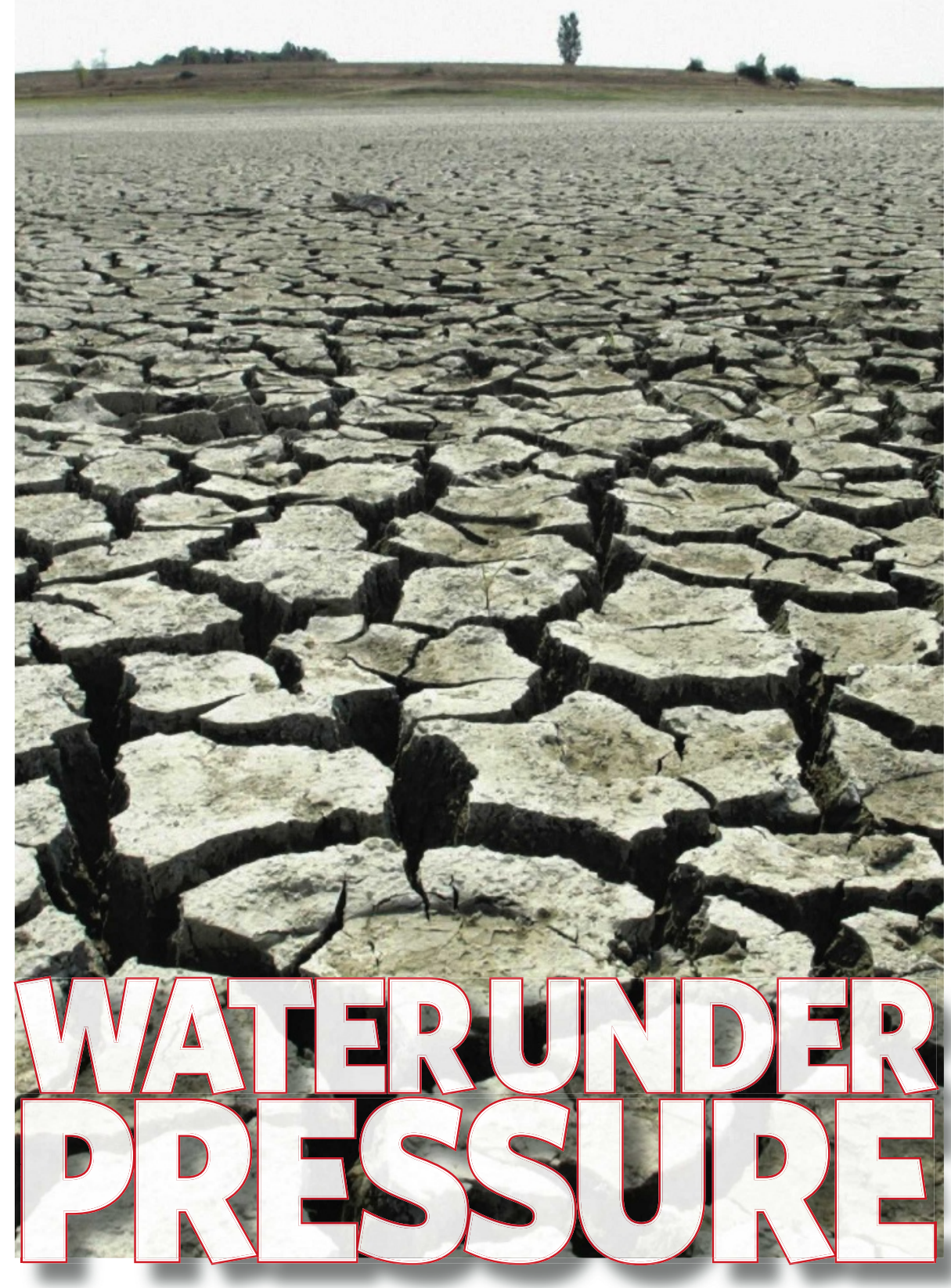

The effects of water shortages are already spilling over from health and sanitation into key economic activities such as agriculture and energy production. Here the challenges are clear, if not fully appreciated: agriculture could easily require twice as much water in the next few decades (see page 273). And the global demand for energy is projected to rise by $57 \%$ by 2030 (see page 285 ).

It we want to improve global access, it is time to rethink our strategies to water, and to respond to global trends in food and energy production.

New concepts are emerging, with experts and policy-makers stressing simple solutions to improve crop yields in the rain-fed areas where many of the world's rural poor live. This is preferable to expanding the area of irrigated farmland, which is already the biggest consumer of freshwater worldwide.

Growing energy demands will require a more integrated strategy for managing freshwater - to prevent cities and farms, or upstream and downstream users, from coming into conflict. This sort of joined-up policy-making has been sorely lacking, but will be crucial to water management at the river basin, and at both regional and transnational scales (see page 253).

Elsewhere in the issue, a Review Article (see page 301) highlights the purification technologies that scientists hope will improve access to safe drinking water. An Essay (see page 291) explains how physicists still argue over theories about the structure of water. And Books \& Arts reviews a television documentary on the privatization of water supplies (see page 288). 